\title{
St. Petersburg Is Site of E-MRS 1993 Fall Meeting
}

The European Materials Research Society (E-MRS), in conjunction with the Federation of European Materials Societies (f.e.m.s.) and the MatTech EastWest Conference group, will conduct its 1993 Fall Meeting at the Tavria Palace in St. Petersburg, Russia, October 17-21. The site will also host the 4th European East-West Conference \& Exhibition on Materials and Processes, October 18-21.

In addition to providing a venue for discussions on materials advances and the exchange of scientific and technological knowledge, the meeting aims to promote East-West industrial and research relations and tap the potential for EastWest scientific collaboration. The program includes a plenary meeting, seven symposia, the exhibition, and round table meetings. Of special interest will be a series of excursions to more than $30 \mathrm{St}$. Petersburg-area industries and research centers. These facilities will be open for visitation, providing a singular opportunity for discussing potential business and scientific cooperative ventures.

This fourth European conference-exhibition is organized in the same spirit as previous meetings, but is being held for the first time in Russia under the auspices of the mayor of St. Petersburg, the

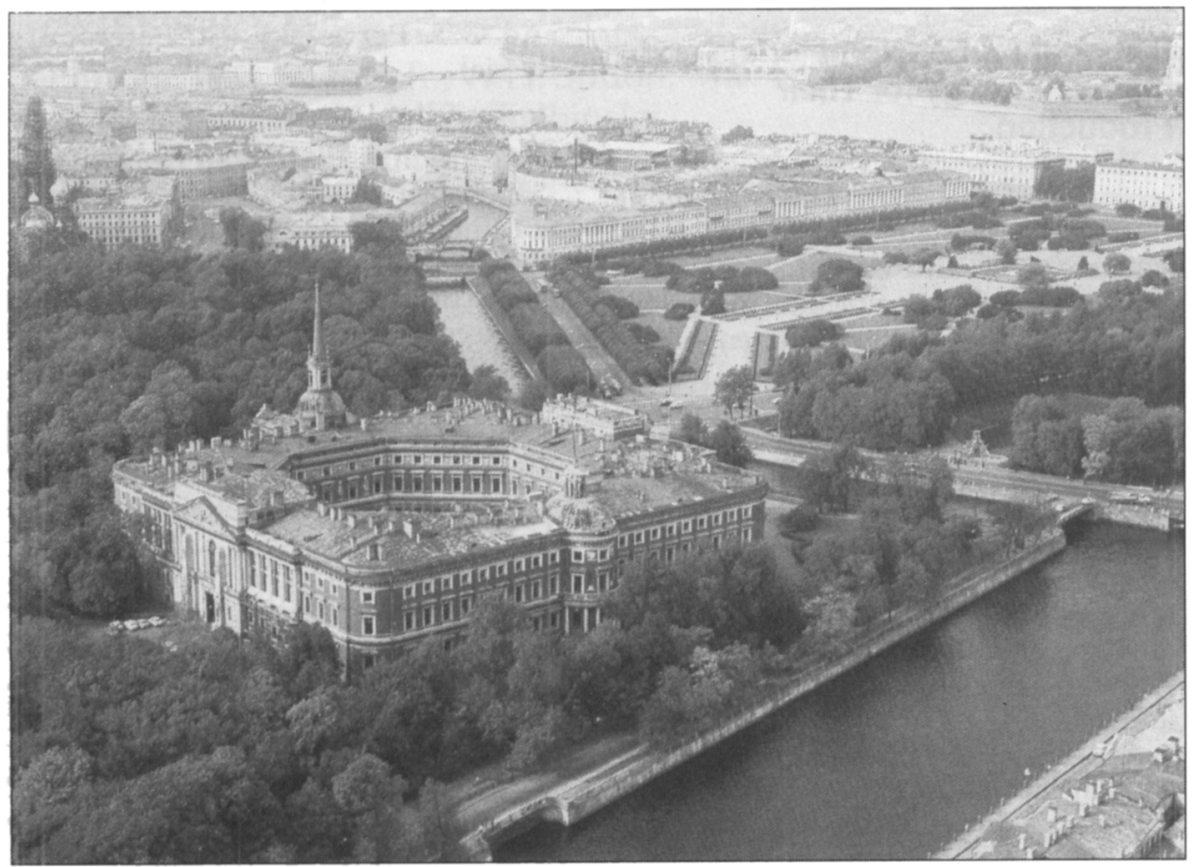

The Mikhailovski (Engineers') Castle (1797-1800), St. Petersburg, Russia
Russian Ministry of Science, the Russian Academy of Sciences, the Ukrainian Academy of Sciences, the Central Research Institute of Structural Materials "Prometey," the Commission of the European Communities, the European Parliament, and the Council of Europe, in addition to E-MRS, f.e.m.s., and MatTech.

A distinctive highlight of the meeting will be the large number of scientists, engineers, and industrial experts from the countries of the former U.S.S.R. Notably, the event will host a sizable contingent of representatives from previously military-oriented laboratories and industries, providing a unique view of the scientific and technological achievements of former U.S.S.R. countries.

The meeting will also feature graduate student awards (up to two per symposium) for graduate students conducting research on topics to be presented at the appropriate symposia. An award consists of 100 ECUs, a diploma, and waiving of meeting registration fees. The deadline for applications is September 15, 1993. Application forms can be obtained from: E-MRS Secretariat, Student Awards, BP 20, 67037 Strasbourg Cédex 2, France; fax 33-88-28-62-93.

Both Eastern and Western companies are participating in the equipment exhibition, whose main purpose is to promote contacts among designers of new materials, equipment, technologies, methods, and new concepts, as well as among innovation-minded enterprises, $R \& D$ centers, and companies interested in establishing different forms of scientific, technical, and commercial cooperation or joint ventures. Exhibition categories include:

- Advanced ultrapure rare materials,

- Testing and characterization of materials and quality control systems,

- Advanced technologies and systems,

- Catalytic materials,

- Biomaterials for implants,

- Optical materials and laser

techniques, and

- Ceramics and ceramic matrix composites.

Application areas of the exhibit include:

- Nuclear technology,

- Telecommunications,

- Electronics,

- Catalysis,

- Transportation,

- Nonwaste technologies (raw materials, energy, environment),

- Protection of monuments, and

- Various innovations.

Companies interested in participating as exhibitors should contact the MatTech Coordination Centre (at the Helsinki University of Technology), P. Attila, 358451-27-82; fax 358-451-27-99.

For a brochure containing information on registration, exhibition particulars, hotels, fees, and other details, please contact: P. Siffert, E-MRS 1993 Fall Meeting, BP 20, 67037 Strasbourg Cédex 2, France; phone 33-88-28-63-72; fax 33-88-28-63-43. Registration fees for the meeting are lower before September 10.

\section{Symposium A-Catalytic Materials and Coatings}

Symposium A will focus on the application of novel materials in catalysis, the use of uncommon catalysts (cellular blocks, foam materials, chemical reactor vessel coatings, etc.) in catalytic processes, and the use of various types of waste for producing catalysts. The accent will be on catalytic processes and on environmentally friendly methods for materials manufacturing. Other topics to be covered are:

- The synthesis and properties of catalysts, and ways of producing catalysts, 
- Molding complicated external geometries, and

- The influence of reaction media on the structure and properties of catalytic materials.

Chairs: E. Derouane (Namur, Belgium), Z.R. Ismagilov (Novosibirsk, Russia), and E.N. Yurchenko (St. Petersburg, Russia).

\section{Symposium B-Ceramic Materials, Including in the Automobile}

Ceramics are playing a growing role in commercial applications, particularly for vehicles. This symposium covers common design problems, questions of reliability, production cost considerations, and performance testing. Main topics will be:

- Ceramic components in batteries and fuel cells,

- Ceramic sensors,

- Ceramic actuators,

- Ceramics for use in hot engine components, and

- Predictions of performance lifetimes for functional and structural ceramic components.

Chairs: P. Boch (Paris, France), R.J. Brook (Oxford, United Kingdom), R. Metselaar (Eindhoven, The Netherlands), A.G. Romashin (Obninsk, Russia), $H$. Thomass (Munich, Germany), and V.I. Trefilov (Kiev, Ukraine).

\section{Symposium C-Manufacturing Process Control and Qualification of Advanced Materials; and, Requirements of a Material for a Specific Application}

The successful implementation of advanced materials in the manufacture of innovative and complex components and products is critically dependent on the understanding and control of both the materials and the manufacturing process steps-and their interaction. This symposium aims to bring together industrial and academic researchers and engineers working in all areas of applicationspecific materials design, characterization, qualification, and lifecycle management. The symposium will highlight both basic studies and applications. Presentations are planned in the following areas:

- Application-specific materials design,

- Materials qualification,

- Manufacturing process control,

- Correlation between the manufactur- ing route and final product quality,

- Nondestructive evaluation,

- Lifecycle management,

- Choice of application-specific material,

- Test systems for structural materials, and

- Degradation mechanisms.

Chairs: G.M. Crean (Cork, Ireland), G.P. Karzov (St. Petersburg, Russia), E. Lange (Petten, The Netherlands), and R. Stuck (Strasbourg, France).

\section{Symposium D-Materials under Extreme Conditions}

The following problems concerning the development and application of new materials in nuclear power engineering, electronics, telecommunications, transport, and other fields will be discussed:

- Service performance of materials under high pressure, variable high and low temperatures in different corrosion media and physical fields, electromagnetic, electron, ion, and neutron irradiation, and the combined effect of all these factors;

- Retention of materials properties during service;

- Technologies providing high quality in the manufacturing of materials, and semifinished and final products; and - The efficiency, as well as ecological safety, of manufacturing.

Chairs: G. Kostorz (Zurich, Switzerland) and V.P. Kuznetsov (St. Petersburg, Russia).

\section{Symposium E-Biomaterials and the Technology for Their Production}

The objective of this symposium is to strengthen scientific links between Eastern and Western European biomaterials research and industry. Ongoing challenges in this area include disposable medical devices and the treatment of biomedical-device waste residues. The role of the environment in the development and course of diseases will be considered, as will the role of sensors in disease diagnosis and treatment. Other topics to be considered are:

- Biological and artificial materials for orthopedy, traumatology, ophthalmology, cardiology, etc.,

- Smart biomaterials and intelligent implants,

- Active wound dressing (artificial skin),

- Artificial blood and body fluids, and

- Industrial impact of biomaterials.
Chairs: V.L. Andrianov (St. PetersburgPushkin, Russia), F. Burny (Brussels, Belgium), and D. Muster (Strasbourg, France).

\section{Symposium F-Optical Materials and Laser Technology for Telecommunications}

The work of the research community on optical materials, lasers, and applications is causing optical telecommunication to become a reality. A review of the state of the art in optical and laser technology will be presented in this symposium. Specific topics are:

- Optical Materials: Fibers-single mode glass fibers, doped fibers (erbium, fluoride), and nonlinear effects in fibers; Dielectrics-for optoelectronic devices, and for passive devices (guides and mirrors); $I I I-V$ semiconductors-materials for emitters, materials for detectors, and materials for amplifiers and modulators; Polymers-molecules with large optical nonlinearities, and polymers as a matrix for nonlinear molecules for active and passive devices.

- Solid-State Lasers and Applications: Lasers-new structures in semiconductor lasers (stained MOW lasers, gain-coupled DFB lasers, etc.), surface-emitting and high-power lasers, short-wavelength lasers, and mini solid-state lasers; Applications-laser diodes for pumping, wavelength multiplexing, optical switches, and nonlinear optics.

Chairs: Y.I. Nissim (Bagneux, France) and G.T. Petrovsky (St. Petersburg, Russia).

\section{Symposium G-Materials for Cultural and Historical Heritage}

Problems dealing with ecology protection and restoration of historical and cultural monuments and museum pieces will be discussed:

- The condition of existing architectural monuments, sculptures, and museum collections in modern industrial cities, - Requirements for preserving the original materials of monuments, and restoration and conservation materials, and

- New materials and technologies for restoring and preserving architectural monuments, city sculpture, and museum exhibits.

Chairs: V.A. Gusev (St. Petersburg, Russia) and A. Tomaszewski (Warsaw, Poland). 